\title{
The Canterbury Earthquakes and refugee communities
}

\author{
Jay Marlowe and Lucy Lou
}

Dr Jay Marlowe, RSW, is a senior lecturer within the School of Counselling, Human Services and Social Work at the University of Auckland. Lucy Lou is a Master of Social Work (Professional) student at the University of Auckland.

\section{Abstract}

The Canterbury earthquakes and subsequent aftershocks have presented a number of challenges for resettled refugee communities living in this region. These events highlight the need to recognise the diversity within culturally and linguistically diverse (CALD) populations for effective disaster preparedness and response initiatives. This paper presents a pilot study of focus groups conducted with the Ethiopian, Afghan and Bhutanese communities about their perspectives and responses to this particular disaster. The participant comments illustrate both the forms of resilience and potential vulnerabilities within these distinct communities and reveal how social work can play an important role in disaster risk reduction strategies.

\section{Introduction}

In early 2011, Christchurch was still recovering from the widespread damage done by the magnitude 7.1 September 2010 earthquake when it was hit by a magnitude 6.3 earthquake on February 22 (McLean, Oughton, Ellis, Wakelin, \& Rubin, 2012). The combination of the timing, shallow depth and closeness to the epicentre meant that the damage was far worse (Corin, 2011). The central business district was devastated, electricity and water were cut in large areas of the city, and 185 lives were lost, making it the second deadliest natural disaster in New Zealand's history (Corin, 2011).

Prior to the September 2010 earthquake, Christchurch was one of New Zealand's principal resettlement localities for people from refugee backgrounds. The recovery efforts following the September 2010 and February 2011 earthquakes have revealed significant gaps in the post-disaster response for CALD communities, and also suggest the need for more effective pre-disaster capacity building (Christchurch Migrant Inter-Agency Group, 2011; Wylie, 2012). To better inform disaster risk reduction strategies with resettled refugee background communities, there is a need to further consider their experiences, strengths and potential vulnerabilities.

As a first step in this endeavour, this paper reports upon post-quake focus group discussions with three of the largest refugee background groups in the Christchurch area: Afghan, Ethiopian and Bhutanese communities. This paper first outlines two recent reports about working with diversity in the Canterbury area and then presents what these three communities discussed in the focus groups to examine what disaster preparedness might entail with CALD populations. 


\section{Literature review and context}

\section{Refugee resettlement in Aotearoa New Zealand}

According to the United Nations High Commissioner for Refugees (UNHCR, 2012), there are more than 15.2 million refugees worldwide. Having refugee status affords individuals access to critical support and resources from the 148 states signatory to the 1951 Convention and its 1967 Protocol (UNHCR, 2012). New Zealand is signatory to this convention and has operated on an annual quota of 750 refugees for permanent resettlement since 1987. The 1951 United Nations Convention Relating to the Status of Refugees formally defined a refugee as:

... a person who is outside his or her country of nationality or habitual residence; has a well-founded fear of persecution because of his or her race, religion, nationality, membership of a particular social group or political opinion; and is unable to avail himself or herself of the protection of that country, or to return there, for fear of persecution (UNHCR, 2012, p. 114).

Over the past five years countries such as New Zealand, the United States and Australia have provided 455,000 refugees the opportunity to resettle (UNHCR, 2012). Though the people who are resettled represent less than one percent of refugees worldwide, resettlement offers a durable solution whereby people can begin a new life free from previous untenable and unsafe circumstances.

It is estimated that over 50,000 people have been resettled in New Zealand since World War II (Ministry of Health, 2012). In the past decade alone, 7,305 people from 55 countries have been received through the quota refugee programme, with the seven top source countries being Afghanistan, Burma, Iraq, Somalia, Bhutan, Iran and Ethiopia. While Auckland receives the majority of quota refugees, Christchurch has been the third major resettlement city, receiving more than 1,000 refugees between June 2000 and June 2010 (Ministry of Health, 2012). This resettlement history highlights that disaster preparedness and response must take into account the various forms of diversity that people carry with them.

A person from a refugee background often experiences the challenge of trying to learn a new language whilst adapting to different perspectives on gender roles and how these relate to participating in a new society (Marlowe, 2012), approaches to education (Harris \& Marlowe, 2011; Sampson \& Gifford, 2009) and ways of interacting with the host community (Fozdar, 2009). Alongside the past experiences of flight from their countries of origin, these considerations are important for an informed disaster preparedness and response strategy. Such understandings are important, not only in terms of potential psychological vulnerabilities due to the past trauma (Fenta, Hyman, \& Noh, 2004; Kirmayer \& Kienzler, 2010), but also as a source of resilience and indigenous knowledge (Marlowe \& Adamson, 2011; Rousseau \& Measham, 2007). As such, learnings about refugee groups could help inform additional strategies that could be of assistance to the wider society and address the particular needs of groups differing across gender, linguistic competencies, employment status and educational background.

However, there has been relatively little literature examining the experiences, perspectives and responses of refugee communities impacted by natural disasters. Most of this literature is situated in refugee camps and other areas of displacement (Goenjian, et al., 2000; Gozdziak, 2004). Within resettlement contexts there is a significant gap with respect to understanding how refugee communities are prepared and able to respond to natural 
disasters. This relative lacuna makes it difficult to determine how best to develop proactive and informed disaster risk reduction approaches with CALD communities.

\section{Local context}

Local, national and international organisations responded quickly to the February earthquake, and the grassroots response and intra-community support that sprang up in the wake of the disaster were inspiring indicators of the resilience of local Christchurch communities (McLean, et al., 2012). However, the response and recovery efforts have not been without their problems, and it is of particular relevance to review the response as it affected CALD and refugee communities. The Christchurch Migrant Inter-Agency Group: Lessons Learned Following the Earthquakes of 22 February 2011 report (Christchurch Migrant Inter-Agency Group, 2011) and the Best Practice Guidelines: Engaging with Culturally and Linguistically Diverse (CALD) Communities in Times of Disaster report (Wylie, 2012) describe and make suggestions for specific issues encountered by those from CALD communities and non-English speaking backgrounds (NESB) after the February 22nd quake. These reports were unanimous in many key recommendations, such as: developing and maintaining existing relationships with groups and communities prior to emergency situations; making use of community gathering places like marae as recovery centres; diversifying communication channels; making use of community radio; and maintaining databases of particular community leader contact details.

A major barrier in the initial stages of the response cited by both reports was the lack of simple English and non-English official and health and safety communications. The Christchurch Migrant Inter-Agency Group (2011) noted that the initial Ministry of Civil Defence and Emergency Management communications were written at English reading levels of 17-18 years, making it difficult to understand for not only the nearly 40,000 NESB residents in the greater Christchurch area, but also many 'native' New Zealanders who function at lower literacy levels (Christchurch Migrant Inter-Agency Group, 2011). This report maintains that the provision of simple and easily translated English materials at the beginning (following September 2010) would have helped both the users of the information as well as translators and interpreters working to support NESB communities (Christchurch Migrant Inter-Agency Group, 2011).

These reports also suggest that limited cultural sensitivity and an inability to communicate hindered the establishment of working relationships between generalist agencies and CALD communities. The Best Practices Guidelines emphasised the need to make better use of interpreters and for individual agencies to include CALD liaison roles and to employ persons from diverse backgrounds (Wylie, 2012). Additionally, the Lessons Learned report noted the importance of strong links to tangata whenua organisations, marae, and the presence of Maori Wardens at recovery centres. Māori understanding of cultural sensitivity was very much appreciated by migrant groups given the lack of cultural awareness training among many of the recovery personnel (Christchurch Migrant Inter-Agency Group, 2011).

Both reports noted the importance and strength of community leadership and the self-support that developed within communities. Good community leaders were able to liaise with outside organisations and provide information and support to their communities (Wylie, 2012). However, not every community had such points of contact with organisations and some groups received little or no outside support in the wake of the earthquakes (Osman, 
Hornblow, Macleod, \& Coope, 2012; Wylie, 2012). This situation highlights the need to consider the diversity that exists within particular localities as a cornerstone of any disaster risk reduction strategy.

\section{What is important in disaster preparedness and response?}

To inform future disaster response and recovery, the Best Practices Guidelines outline ways in which to involve CALD communities in the rebuild effort. A key recommendation is the maintenance of relationships with these communities during the disaster response and for their continued participation in the recovery effort. Some of the suggested actions included: making continued use of community radio stations; creating a dedicated web-based hub; offering resources locally; making spaces for communities to gather and hold cultural events; consulting directly with communities about the rebuild effort; and involving refugees in capacity building initiatives. To achieve many of these points, this report again noted the need for the effective use of interpreters as well as appropriate ways of addressing certain groups that consider cultural and religious practices, lived traumatic experiences, literacy levels, potential forms of vulnerability and the availability of CALD media (Wylie, 2012).

On the other end of the spectrum, the Hyogo Framework for Action is an international document that aims to make suggestions for the reduction of vulnerabilities and hazard risks, and improve disaster response through five identified priorities for action that should be enacted at all levels - from local to national to international (UNISDR, 2005). Its breadth allows for the adaptation of its priorities to many local situations and types of disasters and vulnerabilities, but it also means that specific groups like refugee and CALD communities are not necessarily provided special focus or priority. Whilst the Framework notes the over-arching importance of considering cultural diversity, gender, age and vulnerable groups in the fulfilment of all the priorities for action (UNISDR, 2005), it does not provide specific details on how this is to be done.

Within the New Zealand context, The New Zealand Progress Report on the Implementation of the Hyogo Framework for Action (2009-2011) (Hamilton, 2011) reports on the status of the fulfilment of the priorities of action locally, though it does not provide much more detail on the treatment for cultural diversity. For instance, the specific focus of 'vulnerable groups' was primarily limited to those in disaster-prone areas and those in poverty or with low income and employment levels. While such circumstances are important and common parts of the experiences of refugees in New Zealand (Searle, Prouse, L'Ami, Gray, \& Gruner, 2012), the limited regard for other aspects of diversity in the progress report represents an important knowledge gap on local and national levels. It is in this acknowledgement and celebration of diversity that this paper attempts to uncover what it might mean for the social work profession to work alongside refugee communities in a disaster context.

\section{Study design}

The semi-structured focus group discussions looked to ascertain the specific refugee background community responses to the earthquakes, opportunities to participate in civil society and perspectives of organisational support. This study was conducted with New Zealand's principal refugee resettlement agency, Refugee Services Aotearoa. A staff member from this agency contacted community leaders from refugee backgrounds about the project who then spoke to their respective communities as a form of third-party recruitment. All participants 
received a \$30 grocery voucher and the focus groups were conducted with the Bhutanese, Afghan and Ethiopian communities. Whilst terms such as Afghan and Ethiopian are used in this paper, it must be recognised that there are often important ethnic distinctions within such national identities, though it is not within the breadth of this paper to cover these.

A total of 26 participants took part in these focus groups during January 2012. The focus group discussions were transcribed and analysed through a process of initial and focused coding to develop key themes as outlined by Charmaz (2006).

\section{Results}

The primary themes arising from the focus groups related to perspectives on belonging, responses to the earthquakes and the need to recognise the diversity that exists within refugee groups. In particular, the participant voices highlight that the term 'refugee' is only a starting point to consider the diversity within particular communities. For instance, there was significant variation in the length of settlement within Christchurch and the movements of the communities to other localities following the earthquakes. The participants noted the following information about the recent movements of their respective communities:

- Afghan (approximately 650): arrived from the late 1990s, very little change in numbers leaving after the earthquake;

- Ethiopian (approximately 150 members): arrived in the mid-1990s, estimated that half of community had left after the earthquakes; and

- Bhutanese (approximately 250 members): arrived after 2008, very few people have left after the earthquakes but it remains unclear if they will stay or go.

These numbers were estimates from the community members themselves. The 2011 Census was cancelled due to the February 22nd earthquake and there are no current or highly reliable statistics that pertain to refugee numbers living in the Canterbury region. Whilst the numbers given are participant estimates, the communities' perceived numbers living in the region do provide an insight into how these events have impacted on their relatively small local communities and how they have affected their perspectives on belonging in Christchurch.

\section{Belonging - before and after the earthquakes}

Overall, participants noted feeling that they belonged in Christchurch but this sentiment predominantly related to the physical place itself rather than their relations with the wider community. They expressed positive feelings towards Christchurch because of the opportunity to start a new life:

We know the place and everything so it's very hard to leave and go - we start our life here... we love Christchurch (Bhutanese).

With respect to perspectives on the connections with people, all three groups expressed a strong sense of belonging and solidarity within their own ethnic groupings. In contrast, these relationships were limited with the wider Christchurch community prior to the earthquakes:

New Zealanders... Too much quiet I call them and they keep it to themselves (Ethiopian). 
Almost all participants noted that it was initially very difficult to know people outside their ethnic community. After the earthquakes, however, all three communities stated that the earthquakes had brought them closer to the wider Christchurch community and for some it was the first time that they had met their neighbours. In this sense, a common experience created a form of solidarity where people were supporting one another:

The earthquakes have brought a lot of kindness to each other (Bhutanese).

But when everything happened they came and knocked my door... They came and help us. That's my first experience to know them, how they cared. After earthquake all of them become, like my neighbours, I call them they're too much friendly! (Ethiopian).

In a related example, the Afghan community emphasised that many of them are taxi drivers and that, prior to the earthquakes, they had numerous experiences of people not paying the associated cab fare. Since the earthquakes, they said that this had not happened once, suggesting that the earthquakes had brought people closer - even across difference.

\section{Responding to the earthquakes and recognising diversity}

With respect to what was most helpful to these communities in responding to the earthquakes and aftershocks, all three communities expressed the importance of having their local ethnic community around them as a form of support. They noted that their collective past experiences provided them with some resiliency, allowing them to view the current situation relative to the sometimes more traumatic experiences of their lives pre-migration:

We passed so many bigger issues back at home ... (Afghan).

If you compare the opportunities to our life, that's nothing. We would like to stay here... (Bhutanese).

There is in each of us, because of the earthquake, why we didn't leave. We passed so many bigger issues back at home - we don't scare after earthquake, that's nature things and we need to respect it and live with it (Afghan).

Several participants provided a distinction between natural disasters - which do not target people - and the persecution they faced in their home countries for what they believed or who they were. Along with this collective solidarity, the three groups also noted the importance of a physical meeting centre as a place where their community can gather, support each other in culturally responsive ways and disseminate accurate information. However, these three groups had different access to such a meeting centre: the Afghan community was served by a functioning and self-owned centre pre- and post-quake, the Ethiopian community suffered a temporary loss in functionality of their centre immediately post-quake, and the Bhutanese community lacked a community centre. The Afghan centre provided opportunities to disseminate information about the earthquakes and also reduced the burden placed on local leaders to be the primary response personnel as information sharing, leadership and support was shared across multiple people.

Whilst ethnic group identities demonstrated some differences across their perspectives and responses to the disaster and subsequent recovery, it is important to recognise the rich diversity within these ethnic groups. In particular, considerations of gender, age, time re- 
settled and linguistic competencies (in English) were highly relevant for how the disaster context unfolded for individuals and families. For example, the study included women in both the Bhutanese and Ethiopian groups, and these communities noted that women were less likely to have a driver's licence, be employed or speak fluent English and often take primary responsibility for care of their children. The lack of mobility and limited opportunities for external resources, the focus groups emphasised, could make it difficult for women to receive information and also find ways to respond. One female participant noted there might be different challenges to consider for some women in disaster contexts:

Those women have no idea how to drive and - small kids, looking after their small kids, single mother with kids... Very difficult (Bhutanese).

Others noted the importance of linguistic competencies and age. Those who could not speak English were potentially further isolated with damaged telecommunication systems and compromised infrastructure. Age was also relevant as the young and elderly were less likely to have access to different forms of information sources such as mobile and internet communication technologies, particularly if they did not speak English. Finally, it was also apparent that the Bhutanese community - as the most recent community to settle in Christchurch - found additional challenges to respond, as they did not have the established networks (both internal and external) that had developed over nearly 20 years for the Ethiopian and Afghan groups. These additional considerations provide an important reminder that disaster preparedness requires an analysis beyond ethnicity to other forms of identity and lived experience (employment, education, housing, etc.) that exist within communities.

\section{Discussion - implications for a social work response}

Commenting on what is needed to support positive psychological outcomes after disasters, Kirmayer and Kienzler (2010, p. 168) maintain that 'post-disaster strategies must address the broad impact of disasters, promoting a sense of safety, calming, self and collective efficacy, feelings of connectedness and hope.' The importance of these spaces of safety was evident in the participants' responses and these may vary across gender, ethnicity, language comprehension and age. It highlights the fact that the term 'refugee' is only a starting point and that people's settlement experiences provide critical information about developing effective disaster preparedness and response

Though it is known that former refugees are at risk of mental health issues due to the circumstances of their migration experience (Marlowe, 2009; Tilbury, 2007) in addition to the risk posed by being in a disaster situation (Kayser, Wind, \& Shankar, 2008), the refugee community should not merely be viewed in terms of this risk. The present study has found that participants drew upon their past experiences to put their present situation into perspective. Additionally, Osman et al. (2012) found that most of the Christchurch-area refugees in their study did not experience re-traumatisation caused by the earthquakes as a result of recent experiences triggering traumatic memories. Instead, these authors found religion and spirituality were key factors in coping for many of those participants. At the same time, local organisations like Christchurch Resettlement Services noted a clear and 'unprecedented' need for social work support by the refugee communities they served following the earthquakes (Christchurch Resettlement Services, 2011). The social work role here remains important both in terms of helping to build the capacities within communities to respond 
to particular adversities and also providing an external support when these processes are overwhelmed or unavailable.

In recognition of both the strengths and particular needs of refugee communities, Desai (2007, p. 300), writing from a social work perspective notes some key values in a disaster situation:

- a belief in equality and an ability to identify vulnerability to address issues imposed by crises and ensure equity;

- the importance of people's participation in the disaster response and recovery;

- the right of people to self-worth and self-dignity; and

- a belief in people's capacities to grow and change.

These points highlight the importance of working within communities to strengthen existing relationships and local responses to major events. They also point to the importance of building community capacities before and after the earthquakes (in terms of relationships with the wider community, employment and access to education, etc.). As Thomas, Ott, and Liese (2011) argue, programmes that involve the people and communities impacted by the disaster in the response and subsequent reconstruction and redevelopment should be central to a social work response. Pyles (2007) notes, however, that social work does not necessarily have a strong history of community organising in pre- and post-disaster contexts where people can come together to establish local responses to such events. Drawing upon the experiences and knowledge within communities, therefore, provides critical insight and resources about how to prepare and respond in disaster contexts - particularly in the immediate aftermath when key services and infrastructure may be compromised.

A key anecdote from the post-earthquake experience was the importance to migrant and CALD communities of marae as respected meeting places and of Maori staff in providing a much-needed culturally sensitive response (Christchurch Migrant Inter-Agency Group, 2011). The lack of cultural training among recovery centre staff was revealed to be a great shortcoming by Maori Wardens who were able to identify when cultural needs were not being addressed (Christchurch Migrant Inter-Agency Group, 2011). The Bhutanese community in particular also noted the importance of marae as places to meet with one another and also as sources of receiving information about the disaster response and support from key non-government organisations and government bodies. Such experiences suggest that developing marae as gathering places for refugee communities - particularly for less established groups - may better reach and support these communities in times of disaster. Furthermore, such gathering places could help community disaster preparedness if information and workshops were available there in a targeted and culturally resonant form. The comments from the focus groups also suggest that programmes and workshops to address the needs of women and particularly isolated members of refugee communities may also be beneficial.

The participant comments from this pilot study make powerful statements about belonging to a particular area and present an insight into how social work agencies and professionals can help build relationships within and across communities. Recent studies highlight how meaningful work and educational opportunities represent important markers for successful resettlement (Fozdar, 2012; Searle et al., 2012). Thus, the importance of strengthening com- 
munity resources and relationships needs to be reinforced alongside initiatives that reduce barriers to employment and educational outcomes (Marlowe, 2011). Addressing individuals' inability to understand and communicate in English - noted repeatedly in the earthquake response reports as hindering efforts to support CALD communities and also by former refugees themselves as limiting their employment and community involvement opportunities - remains a key priority. Local organisations like Christchurch Resettlement Services, PEETO and English Language Partners among others are already in place responding to this need and highlight the importance of utilising and resourcing such critical services.

As the specific reports discussed demonstrate (Ferguson, 2011; McLean et al., 2012; Ministry of Health, 2012; Searle et al., 2012; Wylie, 2012) and the participants from the present study reiterated, many of the factors affecting refugees' ability to cope with disaster situations were present before and continue in their lives after - such as English ability, access to affordable housing, employment and experiences of discrimination. Thus, disaster preparedness requires long-term vision that begins well before a disaster event occurs and follows through its aftermath to build community capacities in the subsequent recovery. In this respect, the social work profession's strength in collaboratively assessing community sources of resilience alongside potential vulnerabilities for disaster preparation provides a helpful way forward when partnering with refugee background communities.

The participants from the Afghan, Ethiopian and Bhutanese communities inform the suggestions within this paper and these must be interpreted cautiously as only one focus group was conducted with each respective community. Furthermore, these discussions were conducted in English and highlight that further studies are needed with refugee groups addressing the associated diversity within these groups. In response, a related project using an action research methodology has received more substantial funding to work with research assistants from refugee backgrounds to conduct interviews and focus groups with the different communities living in Christchurch: Kurdish, Nepalese, Bhutanese, Afghan, Ethiopian, Somali and Eritrean. The project will also involve speaking with key service providers about organisational responses and the hope is that this project will help inform disaster risk reduction strategies on local, national and international levels.

\section{Conclusion}

New Zealand has played an important role in resettling refugees living in untenable situations since World War II. As we continue to welcome people with refugee status, the need to consider their diversity becomes increasingly relevant for any disaster risk reduction strategy and effective social work response. The process of developing relationships across refugee background communities generally and the need to acknowledge diversity within these groups specifically signals a critical role for disaster risk reduction.

As has been shown here, there is a wide gap between what are often vague international guidelines and specifically targeted reports on local responses to CALD and refugee communities. This gap highlights the needs of programmes to increase refugee involvement and self-sufficiency within and beyond their ethnic communities, including initiatives that build upon education and employment prospects. Social work has a unique opportunity here to help address this issue and develop meaningful relationships and dialogue with refugee background communities to help build resilience and self-efficacy as part of disaster 
preparedness, response and subsequent recovery efforts. However, the experiences of refugees, service providers and responders in the Christchurch earthquakes have shown that the diversity of refugee communities - both in terms of cultural and linguistic backgrounds as well as other socioeconomic factors - mean that the development of these relationships can take considerable time and must acknowledge the specific needs of each community. It is important, therefore, to take into account and honour specific communities' stories, experiences and hopes for the future in the development of effective disaster preparedness and response initiatives.

Acknowledgements. We would like to acknowledge the assistance of Anne-Marie Reynolds from Refugee Services Aotearoa who helped with third-party recruitment and advice in the analysis phase. This project was supported by a University of Auckland small-scale research grant.

\section{References}

Charmaz, K. (2006). Constructing grounded theory. London, UK: Sage Publications.

Christchurch Migrant Inter-Agency Group. (2011). Christchurch Migrant Inter-Agency Group: Lessons learned following the earthquakes of 22 February 2011. Christchurch, NZ: Christchurch Migrant Inter-Agency Network.

Christchurch Resettlement Services. (2011). Annual Report 2011/12. Christchurch, NZ.

Corin, C. (2011). Practice notes: The Christchurch Hospital Social Work Service response in the first hours after the Christchurch earthquake of 22nd February 2011. Aotearoa New Zealand Social Work, 23(4), 58-62.

Desai, A. (2007). Disaster and social work responses. In L. Dominelli (Ed.), Revitalising communities in a globalised world (pp. 297-314). Burlington, VT: Ashgate Publishing.

Fenta, H., Hyman, I., \& Noh, S. (2004). Determinants of depression among Ethiopian immigrants and refugees in Toronto. The Journal of Nervous and Mental Disease, 192, 363-372. doi: 10.1097/01.nmd.0000126729.08179.07.

Ferguson, B. (2011). The Bhutanese refugee resettlement journey - Part 3: Settlement. Wellington, NZ: Department of Labour.

Fozdar, F. (2009). "The Golden Country": Ex-Yugoslav and African refugee experiences of settlement and "depression". Journal of Ethnic and Migration Studies, 35, 1335-1352. doi: 10.1080/13691830903123120.

Fozdar, F. (2012). Social cohesion and skilled Muslim refugees in Australia: Employment, social capital and discrimination. Journal of Sociology, 48(2), 167-186. doi: 10.1177/1440783311413482.

Goenjian, A. K., Steinberg, A. M., Najarian, L. M., Fairbanks, L. A., Tashjian, M., \& Pynoos, R. S. (2000). Prospective study of posttraumatic stress, anxiety, and depressive reactions after earthquake and political violence. American Journal of Psychiatry, 157(6), 911-916.

Gozdziak, E. M. (2004). Training refugee mental health providers: Ethnography as a bridge to multicultural practice. Human Organization, 63(2), 203-210. doi: 10.1016/0277-9536(89)90281-5.

Hamilton, J. (2011). New Zealand national progress report on the implementation of the Hyogo Framework for Action (20092011). Wellington, NZ: Ministry of Civil Defence \& Emergency Management.

Harris, V., \& Marlowe, J. (2011). Hard yards and high hopes: The educational challenges of African refugee students in Australia. International Journal of Teaching and Learning in Higher Education, 23(2), 186-196.

Kayser, K., Wind, L., \& Shankar, R. A. (2008). Disaster relief within a collectivistic context: Supporting resilience after the tsunami in South India. Journal of Social Service Research, 34(3), 87.

Kirmayer, L., \& Kienzler, H. (2010). Trauma and disasters in social and cultural context. In D. B. Craig Morgan (Ed.), Principles of Social Psychiatry (2nd ed.). Chichester, UK: John Wiley \& Sons.

Marlowe, J. (2009). Conceptualising refugee resettlement in contested landscapes. Australasian Review of African Studies, 30(2), 128-151.

Marlowe, J. (2011). Sudanese settlement: Employing strategies of intercultural contact and cultural maintenance. Australasian Review of African Studies, 32(2), 101-117.

Marlowe, J. (2012). “Walking the line": Southern Sudanese masculinities and reconciling one's past with the present. Ethnicities, 12(1), 50-66. doi: 10.1177/1468796811419605.

Marlowe, J., \& Adamson, C. (2011). Teaching trauma: Critically engaging with a troublesome term. Social Work Education, 30(6), 623-634.

McLean, I., Oughton, D., Ellis, S., Wakelin, B., \& Rubin, C. B. (2012). Review of the civil defence emergency management response to the 22 February Christchurch earthquake. Wellington, NZ: Ministry of Civil Defence \& Emergency Management.

Ministry of Health. (2012). Refugee health care: A handbook for professionals. Wellington, NZ: Author.

Osman, M., Hornblow, A., Macleod, S., \& Coope, P. (2012). Christchurch earthquakes: How did former refugees cope? The New Zealand Medical Journal, 125(1357).

Pyles, L. (2007). Community organizing for post-disaster social development: Locating social work. International Social Work, 50(3), 321-333. 
Refugee Services Aotearoa New Zealand. (n.d.). Nationalities of refugees resettled in New Zealand (1944-2008) (Table). Rousseau, C., \& Measham, T. (2007). Posttraumatic suffering as a source of transformation: A clinical perspective. In L. Kirmayer, R. Lemelson, \& M. Barad (Eds.), Understanding trauma: Integrating biological, clinical, and cultural perspectives (pp. 275-293). New York, NY: Cambridge University Press.

Sampson, R., \& Gifford, S. (2009). Place-making, settlement and well-being: The therapeutic landscapes of recently arrived youth with refugee backgrounds. Health $\mathcal{E}$ Place, 16(1), 116-131.

Searle, W., Prouse, E., L'Ami, E., Gray, A., \& Gruner, A. (2012). New land, new life: Long-term settlement of refugees in New Zealand - main report. Wellington, NZ: Ministry of Business, Innovation \& Employment.

Thomas, T., Ott, J. S., \& Liese, H. (2011). Coproduction, participation and satisfaction with rehabilitation services following the 2001 earthquake in Gujarat, India. International Social Work, 54(6), 751.

Tilbury, F. (2007). "I feel I am a bird without wings": Discourses of sadness and loss among East Africans in Western Australia. Identities: Global Studies in Culture and Power, 14, 433-458.

UNHCR. (2012). UNHCR Global Appeal 2012-2013. Geneva, Switzerland: United Nations High Commissioner for Refugees.

UNISDR. (2005, January). Hyogo Framework for Action 2005-2015: Building the resilience of nations and communities to disasters. World Conference on Disaster Reduction. Kobe, Japan: United Nations, International Strategy for Disaster Reduction.

Wylie, S. (2012). Best practice guidelines: Engaging with culturally and linguistically diverse (CALD) communities in times of disaster. Christchurch, NZ: Community Language Information Network Group (CLING). 